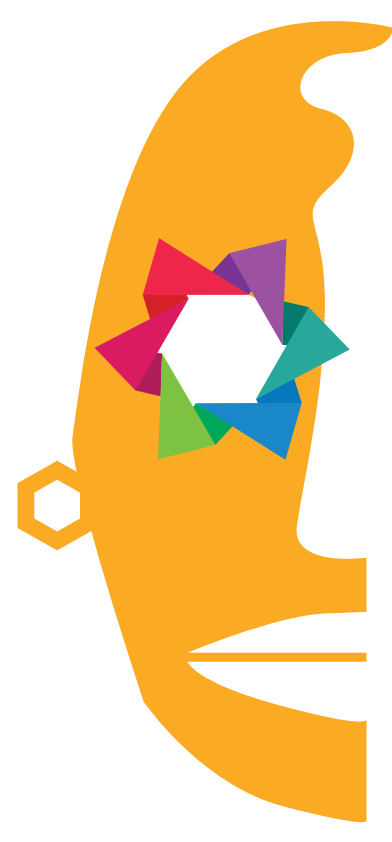

Laura Fuentes

Belgrave

Directora Revista Ístmica

\section{Canibalismo narrativo en relato de Alexandra Pagán}

\author{
Narrative cannibalism in \\ Alexandra Pagán's story
}

En esta edición N. 29 la sección literaria ofrece un guiño caníbal a quienes viven de la literatura, con un cuento de la poeta, narradora y ensayista puertorriqueña, Alexandra Pagán Vélez. Este jugoso aperitivo titulado "Un personaje más", es un relato incluido en su libro Amargo (Secta de los Perros, 2014; $2^{\mathrm{a}}$ ed. de autora, revisada y aumentada en 2018).

Pagán Vélez es también autora de los libros El diccionario y el Capitán (Editorial Preámbulo, 2010), Eneida y Martín: dos coquies muy distintos (libro de cuentos infantil, Santillana, 2018), horror-Real (Instituto de Cultura Puertorriqueña, 2017, en reimpresión), Del Alzheimer y otros demonios (Editorial EDP, 2014), Relatos de domingos (Editorial Espejos de Papel, 2014), y Cuando era niña hablaba como niña (Calamar, 2014). 


\section{Un personaje más Alexandra Pagán Vélez}

A Sonia Ruiz

Desde aquella tarde comprendió que su autobiografía sería un fiasco, un hazmerreír para todos sus ávidos lectores. Ella lo sabía bien, la ficción siempre ha sido mejor que la realidad. No hay nada mejor que colocar todo en un mismo espacio, calcularlo, compactarlo, y simplemente dejarlo ser.

Su primer libro fue una colosal novela que señalaba desde un punto de vista infantil los beneficios del franquismo; fue radical, desinhibida, irreverente y sencillamente, un reto a las conveniencias del pensamiento español. Escribir una novela tan larga apoyando una visión contraria a la suya la colocó en el mismo lugar de otros escritores españoles renombrados del momento. "La mejor y más trabajada ironía hábilmente fundamentada en la inocencia infantil..." esa cita siempre le causaba risa. Inmediatamente tuvo ofertas de varios agentes literarios y para su gusto, escogió al hombre más guapo y elocuente con el que se entrevistó.

Luego escribió la novela, Contigo, que relataba la historia de una empresaria norteamericana quien, absorta en su poder, solo contrataba a secretarios y asistentes guapos. De esta forma, tenía bajo sí un batallón de solteros musculosos que eran la envidia de todo Wall Street. Aunque la mayoría eran homosexuales, su escuadrón ovacionaba el equilibrio corporal, la oficina más bien hacía tributo a Atenas y Miguel Ángel. No obstante, zozobró a manos de los líos amorosos que se suscitaron en la oficina compuesta en su mayoría por homosexuales hermosos. Novios recelosos, infidelidades, heterosexuales que a la larga tuvieron que renunciar o aceptar a sus contrarios, encuentros eróticos con la jefa en las noches de cierre y otros tantos sucesos hicieron de la novela un chiste, un descanso ante las tragedias por las que estaba atravesando el mundo en aquel momento.

No se hizo esperar su libro compuesto por cuentos y memorias de los chilenos del tiempo de Pinochet, Innombrable. De esta colección se destacó el relato, "Sonia" que trata de una estudiante de Antropología que se atrevió a utilizar una cámara inservible de señuelo para fotografiar los campos de concentración. Interesó que la chilena tuviera que exiliarse, precisamente, en Puerto Rico y se uniera a las luchas universitarias de la colonia estadounidense. En una manera este libro sirvió de lazo para unificar dos luchas distantes y al parecer inconexas. Para estos relatos tuvo que viajar un mes a Chile; aprovechó y visitó Argentina lo que dio paso a su cuarto libro Evita y Perón visitan la Tierra del Fuego.

Esta novela ficcionaliza con ingenio un encuentro entre Evita y los yámanas. "Una exploración a la otredad; con el único vínculo de la posibilidad de la maternidad. 
La autora recrea a Evita en su estado más crítico del cáncer uterino y deshace el mito al recrear la mujer", leía la solapa de la edición hispana para Estados Unidos.

Su último éxito fue un análisis al tiempo, hábilmente estudió la diferencia climática, temporal y cultural entre Irak y Washington D. C., y relató la historia de George W. Bush y Abu Musab al Zarqawi. Ambas figuras coinciden en sueños agitados: Bush sueña que su hija, Jenna muere tras ser bombardeada su casa, despierta sobresaltado, pero feliz de que haya sido una pesadilla; el otro, sueña que juega con su bebé de 18 meses, para despertar y llorar hasta morir al ver que solo soñaba y había, en efecto, perdido a su hijo en un bombardeo. Su juego con las circunstancias y perspectivas le dieron un matiz metafísico a la novela que no solo logró conmover, sino cuestionar al presidente de la gran nación norteamericana.

Por otra parte, su última novela no fue tan avalada. Medicina relata la vida de Amanda, una estudiante de Medicina, quien llegó a estudiar un cadáver hasta descubrir que le había conocido en una discoteca hacía muchos años. De allí, Amanda hizo investigaciones hasta dar con la familia de Marcos y descubrir la razón por la que nunca reclamaron sus restos. Ante la desolación y el amor que fue desarrollando hacia ese ser que iba "conociendo", Amanda decidió una noche robar su cadáver y fue descubierta. Ni la crítica ni los lectores apreciaron leer sobre la necrofilia cuando recién habían masacrado Madrid. Fue allí cuando la editorial entendió que era oportuno tener una autobiografía para que "los lectores descubrieran el misterio detrás de las letras".

Esa tarde se sentó, como hacía siempre que tenía que escribir por entrega, frente a la pantalla que llenaba de letras mientras fumaba. Decidió añadir uno, dos, tres, cuatro detalles a su niñez para que fuera más interesante, para que de alguna forma hubiera un conflicto y se creara un ambiente. Cuando salió a comprar comida se topó con una amiga de la infancia y actuó como si lo que hubiese escrito hubiera pasado y dejó desconcertada a la amiga que no entendía por qué le decía aquello.

Así pasaron los meses y la escritora añadía uno, dos, tres, cuatro, cinco hasta diez detalles a su adolescencia. Recreó la pérdida de la virginidad como siempre la soñó para alguno de sus personajes. Hasta se inventó tres aventuras lésbicas que le resultaron realmente eróticas y así siguió asumiendo que lo que escribía era cierto; que había pasado tal como lo relataba. Los amigos cercanos le notaron cierto sex appeal, cierta complicidad y carisma nuevos; apostaban que tenía un romance nuevo, que había logrado bajar de peso o que estaba de nuevo consumiendo cocaína. Sin embargo, ella no admitía su secreto: estaba rehaciendo su vida.

Una vez le tocó hablar sobre su adultez, se decidió a tener tres affaires; viajar a Marruecos, fumar hachís en el atardecer; viajó a Bolivia y se unió a las protestas del momento. Empezaba de pronto a sentirse la fulana de la que estaba 
escribiendo. Cuando regresó a Madrid se dio cuenta de que no era necesario hacer autobiografías de nadie para nadie. Así recobraría su fama y el gusto de la editorial hacia su obra: escribió la historia de una mujer que tenía que hacer su autobiografía y supuso que sería un fiasco, un hazmerreír para todos sus ávidos lectores. Ella lo sabía bien, la ficción siempre ha sido mejor que la realidad. No hay nada mejor que colocar todo en un mismo espacio, calcularlo, compactarlo, y simplemente dejarlo ser. 